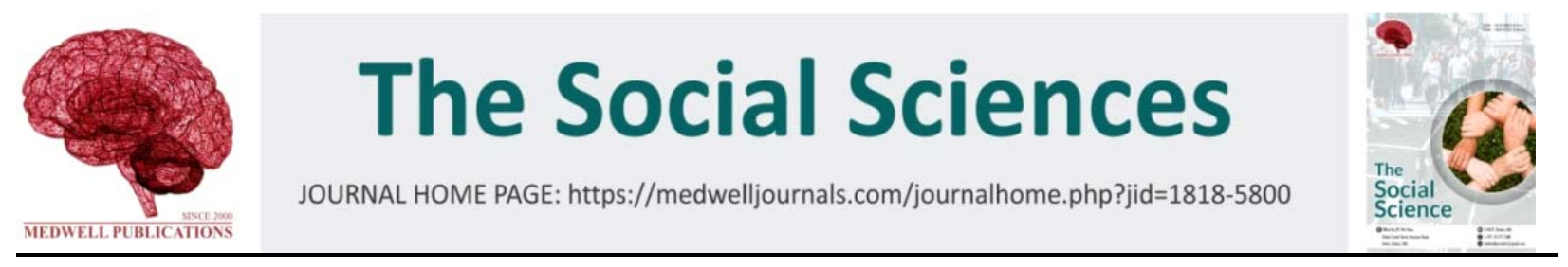

\title{
The Social Construction of Digital Multimedia and the Policy of Mass Media Coverage in the Creation of Hyper-Reality Politics in Indonesia and Malaysia
}

\author{
${ }^{1}$ Basa Alim Tualeka and ${ }^{2}$ Burhan Bungin \\ ${ }^{1}$ College of STISIPOL Candradimuka, Palembang, Indonesia \\ ${ }^{2}$ FISIP University, Surabaya, Indonesia
}

Key words: Social construction, digital multimedia, government policy, mass media, hyper-reality politics, especially

\section{Correspoding Author: \\ Basa Alim Tualeka \\ College of STISIPOL Candradimuka, \\ Palembang, Indonesia}

Page No: 34-37

Volume 15: Issue 1, 2020

The Social Science

ISSN (P): 1818:5800

Copy Right: ( $)$ Medwell Publications

\begin{abstract}
The development of media technology nowadays shows a very rapid progress, especially, the mainstream media that is developing towards digital media that makes the social construction power even more flawless. This progress is very beneficial to the development of society but it can also be used by political interests for control over powers. Against their political opponents, political parties can use this advanced mass media technology to attack and block off counterattacks through social construction or deconstruction. This study uses narrative qualitative approach and interview method by interviewing the informants to explore the understanding of the development of digital multimedia in Indonesia and its practice by Indonesian political parties through, the role of mass media.
\end{abstract}

\section{INTRODUCTION}

The reality of social construction: Media technologies that in this era have given birth to many digital multimedia communications are developing robustly. The society is drowning in euphoria of this technology, economy is growing, taking many advantages from commercial multimedia technology. Yet in politics, some rulers of countries in the Middle East like Iraq, Egypt, Libya, Syria and Yaman are collapsing and there are several more that will follow. The influence of digital multimedia technology and its spectrum are like Ebola which endemically ruins the social and political order and destroys the social order and political relations through freedom of thought, freedom of speech, human rights information transparency and 'misunderstood' democracy.

Then what about Indonesia and Malaysia, the two nations of neighborhood that share one cluster, one culture, one core of language, yet different history in the past? Indonesia in 1998 underwent a terrible experience in the life of a nation, as a result of 'the freedom of press' allowed by Soeharto, through the 'backfire' policy that time. Soeharto fell out of power as a result of the press freedom led by Yunus Yosfiah, the Information Minister back then. People were questioning whether there would be a second wave of 'media storm' engulfing Indonesia. Worriedly we 'wait and see' because when the press freedom was given in Soeharto era and the spread of media technology was not as endemic as now, it was capable of destroying the nation. Then, how about Indonesia today when Indonesia is cramped by mass media technology? I view Indonesian people as a piece of wood eaten by termites of which does not look rotted from the outside, yet has already been destroyed in the inside. Therefore, Indonesia is actually only waiting for its last moment before it collapses. One of the cases is during the last election, mass multimedia technology has split Indonesia into two through multimedia slandering incitement, craftiness and impression making. Social war with the means of multimedia technology has occurred from the elite political level to the level of grassroots and this war continues until now and is even entering the cold war stage.

Malaysia is learning much from what has happened in Indonesia. The more powerful party does not take risks of opening press freedom broadly like Indonesia. However, media in Malaysia is very aggressive in launching attacks to their enemies. Malaysia is a step forward in seeing the concept of media in digital multimedia understanding, so that, they can see digital multimedia as a part of the cluster of media technologies, 
The Soc. Sci., 15 (1): 34-37, 2020

Table 1: The Construction agents create different realities in social constructions

\begin{tabular}{ll}
\hline Constructing agent/unit & Varieties of constructivism \\
\hline Brain & Neurobiological constructivism (representative: Gerhard Roth) \\
'Cognitive system' observer' & Constructivist bio-epistemology (representative: Humberto R. Maturana) \\
'Social system, communication & Auto-poieticsystem therory (representatives: Niklas Luhmann, Peter Fuchs et al.) \\
Culture & (Constructivist) culturalism (representative: Peter Janich) \\
Media (individual media and mass media systems) & Media-cultural constructivism (representatives: Grbhard Rusch, Klaus Merten et al.) \\
Cognition, communication, media and culture & Socio-cultural constructivism (representative: Siegfried J. Schmidt) \\
\hline Weber, 2002 &
\end{tabular}

making it inseparable one from another. Malaysia pays close attention to mainstream media such as televisions, radios and newspapers and keeps being careful of the spread of digital multimedia like the internet and other social media. This, especially, happens when Malaysian government knows that Anwar Ibrahim, the opposing movement, successfully earned the people's heart through social media, so that in quantity Malaysian people tended to choose political parties in coalition with Anwar Ibrahim during the past election, even though in the end, Ibrahim's coalition lost the distribution of the seats in the parliament (Bandura, 2001).

Paradigmatic perception: Digital multimedia technology successfully influences human cognitive side and it builds a hyper-reality sight inside their minds regarding an ideal nation, ideal figures, ideal democracy as well as about welfares, freedom of speech, freedom of citizenships and so on.

As what Table 1 shows, many constructivists dedicated themselves for various social constructivism values, so that, for the neurobiological constructivist researcher Gerhard Roth, it seemed undeniable that brain is the 'mother' of all reality constructions. Even imaginations, self-reflections and self-conscience are a constructive product of brain as neuro-labelism, as if the 'image' really happens (Weber, 2002). Other three thinkers who focused on main communication, culture or media as a reality-agent that results in constructivism only developed in the variations proposed by Stefanone et al. (2014), Weber (2002), tried to observe all construction agents in a 'closed circuit' which is the human brain (Priyowidodo, 2016).

Thus in reality digital multimedia technology is connected to the nerves system of human's brain. The magnetic wave in digital multimedia technology is connected with millions of nerves system in human brain, resulting images that look real and alive and are there with the human.

Some of the differences in the construction agents create different realities in social constructions: Most of the modern constructivism varieties, especially, those developed in scientific discourses in German, regard themselves as counter-position realism (either covered as naïve, moderate or even radical constructivism) that still dominates intellectual model in scientific works, way of
Table 2: Realistic and constructivist terminology

\begin{tabular}{ll}
\hline Realistic terminology & Constructivist terminology \\
\hline (= mimetic way of thinking) & (= poietic way of thought) \\
Semantic field “depiction” & Semantic field “construction” 5 \\
Depicting & Making \\
Representing & Constructing, generating \\
Copying, imitating & Planning, designing, producing, creating \\
& (re) producing \\
Reflecting, projecting (up) & Embodying, producing, building \\
Discovering (?) & Inventing (?) \\
\hline
\end{tabular}

Weber (2002)

thinking and way of speaking with the depiction of reality paradigm which was latently or surely suggested by majority of researchers. Henceforth, constructivist's way of thinking is read as an antipode of realistic terminology field (Hitoshi, 2013) (Table 2).

\section{MATERIALS AND METHODS}

This research used narrative qualitative method, meaning that this research collected data and reported the research results based on what happened in the field. For data collections, the writer used interview method with four respondents who have profound understanding on the development of digital multimedia in Indonesia as well as how its influences can be utilized by other powers aside from mass media in Indonesia (Priyowidodo et al., 2014).

\section{RESULTS AND DISCUSSION}

Social-political hyper-reality: In Malaysian socialpolitical reality, the mass multimedia technology is used to attack one's political opponents openly. Though it seems that the government is taking control over mainstream media in reality political rivals are attacking each other through mass media and other multimedia. The case of Anwar Ibrahim was attacked from many aspects, especially, from the moral side, the attacks toward Anwar Ibrahim constructed his image as someone who is mentally depraved for conducting sodomy, lacking abilities to organize his family and so on. Also, the attacks of Malay groups to Chinese were stated noticeably in newspapers and televisions by constructing Chinese as those being crabby, etc. (Karasar, 2002).

In Indonesia, by taking the presidential election held couple of months ago as an example, social political hyper-reality constructions were used in all levels. The 
first level is the informational transformation happening between one individual and another. The multimedia internet and social media users exchange information for data consumption amongst themselves.

The second level is the level of constructing the hyper-reality image of the figures (people) supported in the presidential election. At this level, the social-political hyper-reality construction is utilized to give certain images for the political figures or parties joining the election. Hence, that particular time Jokowi was constructed as a representative of the common people, who wear ordinary clothes, becoming becak driver, becoming bicycle repairman or 'blusukan' (the term used for going into some clump areas all over the city) and else. Meanwhile, Prabowo constructed his image along with middle-class outfits, Bung Karno’s way of speech, being a member of the intellectual groups and so on. As a result when all of the phenomena were published in only one media and then repeated by multimedia (including mainstream media, the internet, social media), the power of the social construction folded in times.

The third level is the crime level where in order to construct a hyper-reality image for a figure or a thing, this party intentionally invites the multimedia hackers (even from abroad) to destroy, to trespass through, information media companies for the sake of 'forcing' some certain news they want to appear as the head news of the media companies as well as to destroy the news of their rivals or the thing, anything regarding information they want to hack. In social media, these hackers try to recruit 'false followers' to create opinions with the help of computers and machines in their hands.

The limitation of social-political-hyper-reality: The social-political hyper-reality construction has risky limitations to hold on. It means the ability to construct reality in certain limit will become a weakness that is as big as the reality construction is build. In the theory of mass media social construction (Burhan, 2008), the spread of social construction is determined by the power of mass media. Thus, if the digital multimedia technology constructs social-political hyper-reality and spreads it with full power into all levels of society, the power of social deconstruction which can ruin all the social political hyper-reality construction would also be as big.

Hence, the question would be to what point the power and limitation of the social-political hyper-reality itself are and the answer would be on the power of digital multimedia technology in the society itself. However, a constructivist can play the power of the construction with its authority such as: using as many as possible social construction media as his own media or media which obviously stand on his side with his authority, trying to rule or close other media in oppose or potentially in oppose to him doing actions corresponding and in accordance with the concept of social construction that is being spread through digital multimedia, switching people's attention (that are being constructed) into things which would decay the social construction time, conducting repetition of social-political hyper-reality construction particularly with his own multimedia.

Social construction that is done excessively but in fact people know the real life of the object being constructed would therefore, be very easy to deconstruct socially. To keep being consistent is usually the point where the constructivist or the object of construction become impatient, since, sometimes the image does not go in line with their real lives.

The ethics of social hyper-reality construction: The mass media social construction theory is a neutral theory, like other theories. This theory can be used to increase one's popularity yet can also be used to destroy one's political rival. Therefore, the use of this theory should follow the existing scientific ethics. First, social hyper-reality construction is a reality formed through the social construction theory of mass media, so that, mainstream media contribute in taking responsibility of the spread of social construction's content as a part related to press ethic code in general.

\section{CONCLUSION}

This would be a dilemma if the spread of social construction also happens in social media. However, if it happens, the ethical responsibility is within each individual owning the particular social media. Second, this theory would be useful in one hand to increase the image of someone or something, yet in another hand, being 'riya' (overwhelmed joy and spending), being arrogant, slandering, outwitting others or even deceiving the publics can indeed happen in social construction. That is why the ethical responsibility is solely in the hands of the constructivist agents.

\section{REFERENCES}

Bandura, A., 2001. Social cognitive theory of mass communication. Media Psychol., 3: 265-299.

Burhan, B.M., 2008. Mass Media Social Construction: The Strength of the Influence of Mass Media, Television Advertising and Consumer Decisions and Criticism of Peter l. Berger \& Thomas Luckmann, Kencana Publisher, North Maluku, Indonesia, ISBN:9789791486385, Pages: 255.

Hitoshi, Y., 2013. The construction of reality about media on the internet. Department Sociology, Faculty of Liberal Arts, Teikyo University, Japan.

Karasar, S., 2002. Virtual construction of social reality through new medium-internet. Turkish Online J. Distance Educ., 3: 67-73. 
Priyowidodo, G., 2016. Politics and organization in opposition: Patterns of communication and decision making in parti keadilan Rakyat (The people's justice party) of Malaysia. Soc. Sci., 11: 113-119.

Priyowidodo, G., G. Swestin and T. NurVidyarini, 2014. The faces of conflict in a political organization: the case of the Indonesia democracy party of struggle (Partai Demokrsi Indonesia Perjuangan PDI-P). Mediterr. J. Soc. Sci., 5: 608-618.
Stefanone, M.A. D. Lackaff and D. Rosen, 2014. The relationship between traditional mass media and social media: Reality television as a model for social network site behavior. J. Broadcasting Electron. Media, 54: 508-525.

Weber, S., 2002. [What does media construct reality mean? From an ontological to an empirical understanding of construction (In German)]. J. Mass Commun., 1: 11-16. 